\title{
Dependence of the water retention curve of snow on snow characteristics
}

\author{
Satoru YAMAGUCHI, ${ }^{1}$ Kunio WATANABE, ${ }^{2}$ Takafumi KATSUSHIMA, ${ }^{3}$ Atsushi SATO, ${ }^{1}$ \\ Toshiro KUMAKURA ${ }^{4}$ \\ ${ }^{1}$ Snow and Ice Research Center, National Research Institute for Earth Science and Disaster Prevention, Niigata, Japan \\ E-mail: yamasan@bosai.go.jp \\ ${ }^{2}$ Mie University, Tsu, Mie, Japan \\ ${ }^{3}$ Toyama National College of Technology, Toyama, Japan \\ ${ }^{4}$ Nagaoka University of Technology, Niigata, Japan
}

\begin{abstract}
The water retention curve (WRC), which shows the relationship between the volumetric liquid water content, $\theta_{v}$, and suction, $h$, is a fundamental part of the characterization of hydraulic properties. Therefore, the formulation of the WRC as a function of snow characteristics is essential for establishing a model of water movement through the snow cover. In this study, we measured the WRC of several snow samples, which had different characteristics (grain size, bulk dry density and grain type), using a gravity drainage column experiment and then analysed these data using the Van Genuchten soil physics model (VG model). The shape of the WRC depended strongly on both the sample grain size, $d$, and bulk dry density, $\rho$. Therefore, we introduced the parameter $\rho / d$ to model the WRC of snow. The relationships between the parameters $\alpha$ and $n$ of the VG model and $\rho / d$ change with grain type. For melt forms, $\alpha$, which is related to the inverse value of the air-entry suction, increases quickly as $\rho / d$ decreases, whereas $n$, which is related to the gradient of $\theta_{v} v s h$, increases with $\rho / d$. Conversely, neither of these parameters of the VG model for rounded grains showed obvious dependence on $\rho / d$. These results suggest that water movement through snow cover can be modelled using grain size, bulk dry density and grain type based on the soil physics model.
\end{abstract}

\section{INTRODUCTION}

An accurate description of meltwater movement through snow cover is essential to improve the forecasting of disasters resulting from wet snow. Most water transportation processes in natural snow cover occur under unsaturated conditions because water usually drains from the snowpack before saturation is reached. Therefore, it is important to determine the unsaturated hydraulic conductivity, $K$, based on the snow characteristics. However, directly measuring $K$ of snow is very difficult and only a few attempts have ever been made for a limited set of snow samples (Sugie and Naruse, 2000; S. Yamaguchi and A. Sato, unpublished information). Consequently, fundamental questions regarding how to model $K$ of snow remain unanswered.

The water retention curve (WRC) shows the relationship between the volumetric water content, $\theta_{v}$, and matric potential, $\psi$, or suction, $h$, and is a fundamental part of the hydraulic properties in porous media (Klute, 1986). In soil physics, $K$ is commonly modelled based on WRC measurements (e.g. Mualem, 1976). Several studies have reported measured WRCs of snow (e.g. Colbeck, 1974, 1975; Wankiewicz, 1979), which may be useful for modifying soil physics models to establish a model for $K$ of snow, but only if the hydraulic properties of snow behave similarly to those of soil. Yamaguchi and others (2010) measured the WRCs of snow with the same density but various grain sizes using a gravity drainage column. They found many similarities between the WRCs of snow and sand, on the basis of which they applied widely used soil physics models to analyse the characteristics of the WRC of snow. Using these results, they suggested that the WRC of snow can be described as a function of grain size using soil physics models. Moreover, based on their results, Hirashima and others (2010) introduced a new scheme for calculating water movement through snow cover under unsaturated conditions in the numerical snow-cover model, SNOWPACK, developed by the WSL Institute for Snow and Avalanche Research SLF, Davos, Switzerland (Bartelt and Lehning, 2002; Lehning and others, 2002a,b). They succeeded in reproducing the appearance and disappearance of layers with a high water content in seasonal snow. Although these studies contributed to our understanding of the mechanism of water movement in snow and improved the modelling of water movement through snowpack, Yamaguchi and others (2010) examined only one grain type and one bulk dry density $\left(550 \mathrm{~kg} \mathrm{~m}^{-3}\right)$, which was high relative to that of natural wet snow. To improve understanding of the dependence of snow's hydraulic properties on its physical characteristics, we examined the WRCs for different bulk dry densities and grain properties. Based on our findings, we discuss the possibility of modelling the WRC of snow as a function of grain size, bulk density and grain type.

\section{METHODS}

\subsection{Properties of snow samples}

We used two types of snow sample: screened refrozen melt forms kept in a cold room at $-20^{\circ} \mathrm{C}$ for 1 year (S-sample hereafter) and natural snows obtained in the field at the Snow and Ice Research Center, National Research Institute for Earth Science and Disaster Prevention, Japan (N-sample hereafter). The S-samples had high grain-size uniformity because they were fragmented and screened through several fine-meshed sieves with progressively smaller meshes. The $\mathrm{N}$-sample experiments were conducted on the same day that each snow sample was obtained. To determine the grain 
size, at least 500 individual grains in each sample were photographed through a microscope, and the area of each grain was determined using the ImageJ software developed at the US National Institutes of Health. Then each equivalent grain diameter, which was defined as the diameter of a circle with the same area, was calculated. In this study, the representative grain size for each sample was assumed to be the average diameter, $d$, in the sample (Table 1). Table 1 also presents the uniformity coefficients (UCs), which are a measure of the relative dispersion. Values of UC close to 1 indicate a high level of uniformity. The S-samples had small UCs, whereas the N-samples had large UCs, reflecting a marked difference in uniformity of grain size between the $\mathrm{S}$ and N-samples.

Snow for each S-sample was packed into a sample column that consisted of several acrylic rings $(20 \mathrm{~mm}$ high, $50 \mathrm{~mm}$ in diameter) taped securely together. The bulk density, which is determined by the volume of the sample column and the weight of snow added, was controlled by tamping the snow sample. The S-sample density was high relative to that of the normal seasonal snow density because of repacking. The bulk density of $\mathrm{N}$-samples packed into a sample column without tamping was the same as under natural conditions. To examine the influence of density change, we also performed experiments using $\mathrm{N}$-samples that were tamped to increase the density. If a snow sample was wet, the water content was measured using part of the sample prior to performing the experiment, and the bulk dry density was calculated from the measured bulk density. The dry bulk densities of all the samples are also listed in Table 1.

\subsection{Measurement of water retention curve of snow}

The WRC of snow was measured using a gravity drainage column method (Yamaguchi and others, 2010). First, the column holding the sample was submerged in water with ice at $0^{\circ} \mathrm{C}$ in an insulated box until the snow was saturated (30 min in this study). The water was then removed from the insulated box using a pump until a defined water-table level was reached, and the column was allowed to settle until a steady state was reached at $0^{\circ} \mathrm{C}(60 \mathrm{~min}$ in this study). Finally, the volumetric water content, $\theta_{v}$, for each acrylic ring and the corresponding suction value, $h$, which was defined as the central height of each ring from the final water-table level, were measured to obtain the WRC.

\section{EXPERIMENTAL RESULTS AND DISCUSSION}

\subsection{Influence of grain size and bulk dry density on the WRC of snow}

Figure 1a shows the WRCs and the relationship between the volumetric water content, $\theta_{\mathrm{v}}$, and suction, $h$, for S1-2 (black circles) and S4-2 (white triangles). The figure also gives the plotted data number (DN). The two S-samples had similar dry bulk densities $\left(\mathrm{S} 1-2=555 \mathrm{~kg} \mathrm{~m}^{-3}, \mathrm{~S} 4-2=547 \mathrm{~kg} \mathrm{~m}^{-3}\right)$ but different grain sizes $(\mathrm{S} 1-2=0.5 \mathrm{~mm}, \mathrm{~S} 4-2=2.1 \mathrm{~mm})($ Table 1$)$. The shapes of the WRCs differed markedly for the two samples. We used a soil physical model to analyse the measured WRCs. Yamaguchi and others (2010) applied two widely used soil physics models, the Brooks and Corey model (BC model; Brooks and Corey, 1964) and the Van Genuchten model (VG model; Van Genuchten, 1980), to determine the shape of the WRC of snow. Based on a comparison of the results of the models, they concluded that the VG model reconstructed the distribution of the measured
WRC of snow better than the BC model did, although both models were in good agreement with the experimental WRC for snow. Therefore, we adopted the VG model to analyse the measured WRCs of snow in this study.

The VG model is as follows:

$$
S_{\mathrm{e}}=\frac{\theta_{\mathrm{v}}-\theta_{\mathrm{v}}^{\mathrm{r}}}{\theta_{\mathrm{v}}^{\mathrm{s}}-\theta_{\mathrm{v}}^{\mathrm{r}}}=\left(1+|\alpha h|^{n}\right)^{-m},
$$

where $S_{\mathrm{e}}$ is the effective saturation water content, $h$ is suction, $\theta_{v}$ is the volumetric water content, and $\theta_{v}^{r}$ and $\theta_{v}^{s}$ are the residual and saturated volumetric water content, respectively; these parameters determine the relationship between $\theta_{v}$ and $S_{\mathrm{e}}$, whereas $\alpha, n$ and $m$ are parameters that affect the shape of the WRC. Although several formulas for the relationship between $n$ and $m$ have been suggested (Van Genuchten, 1980; Van Genuchten and Nielsen, 1985), we adopted the standard relationship $m=1-(1 / n)$. To fit the VG models to the measurements, we must determine the parameters $\theta_{v}^{r}, \theta_{v}^{s}, \alpha$ and $n$. In this study, we adopted $\theta_{v}^{r}=0.02$ and $\theta_{v}^{s}=10 \%$ less than the porosity for all samples based on Yamaguchi and others (2010). Finally, parameters $\alpha$ and $n$ of the VG models were determined by applying the models to the experimental results using the Retention Curve (RETC) software (Van Genuchten and others, 1991). The results of the VG model simulation were in good agreement with the experimental results (Figs 1a and 2a), indicating that the VG model is suitable for describing the WRC of snow.

The WRC of a porous medium can be conceptualized using the capillary bundle model, in which pores are treated as a bundle of capillary tubes of varying sizes. Although this model differs in several ways from water flow in real media, it contains many of the properties of a real medium and may be used to understand the relationship between the WRC and the geometry of porous media (Jury and Horton, 2004). Thus, we attempted to explain the difference between the WRC of two samples using the capillary bundle model theory. Because $S_{\mathrm{e}}$ becomes 0 with the minimum capillary tube radius $r_{\min }=0$ and becomes 1 with the maximum capillary tube radius $r_{\max }$, the probability density function of the contribution of each capillary tube, $r$, to the WRC, $p(r)$, is defined as the differentiation of $S_{\mathrm{e}}$ by $r$ as follows:

$$
p(r)=\frac{\mathrm{d} S_{\mathrm{e}}}{\mathrm{d} r}=\frac{1}{\theta_{\mathrm{s}}-\theta_{\mathrm{r}}} \frac{\mathrm{d} \theta}{\mathrm{d} r}=\frac{1}{\theta_{\mathrm{s}}-\theta_{\mathrm{r}}} \frac{\mathrm{d} \theta}{\mathrm{d} h} \frac{\mathrm{d} h}{\mathrm{~d} r} .
$$

The relationship between capillary tube radius, $r$, and suction, $h$, is described by the Laplace equation

$$
h=-\frac{2 \gamma \cos \beta}{\rho_{\mathrm{w}} g r} \text {. }
$$

Here $\gamma$ is the surface tension of water $\left(0.0073 \mathrm{~J} \mathrm{~m}^{-2}\right)$ and $\beta$ is the contact angle between water and ice particles $\left(0^{\circ} \mathrm{C}\right)$. Introducing Eqns (1) and (3) into Eqn (2), $p(r)$ for the VG model is defined as (Mualem, 1976; Kosugi, 1996; Sakai and Toride, 2009)

$$
p(r)=\frac{2 \gamma}{\rho_{\mathrm{w}} g r^{2}} \frac{\alpha^{n m n}(-h)^{n-1}}{\left[1+(-\alpha h)^{n}\right]^{m+1}} .
$$

Finally, the ratio of capillary tubes with a diameter of $r$ to all capillary tubes, $F(r)$, is

$$
F(r)=[p(r) \times \mathrm{d} r] \times 100 .
$$

Figure $1 \mathrm{~b}$ shows $F(r)$ calculated from the VG model simulations. The position of the peak of tube (pore) radius $r$ for $\mathrm{S} 1-2(0.09 \mathrm{~mm})$ is smaller than that for $\mathrm{S} 4-2(0.25 \mathrm{~mm})$, 
Table 1. Sample information. Snow type is according to the International Classification for Seasonal Snow on the Ground (Fierz and others, 2009)

\begin{tabular}{|c|c|c|c|c|c|c|}
\hline \multirow[t]{2}{*}{ Sample type } & Snow type & $d$ & UC & Sample name & $\rho$ & Comment \\
\hline & \multicolumn{3}{|c|}{$10^{-3} \mathrm{~m}$} & \multicolumn{3}{|c|}{$\mathrm{kg} \mathrm{m}^{-3}$} \\
\hline \multirow[t]{19}{*}{ S-sample } & \multirow[t]{19}{*}{ Refrozen melt forms } & \multirow[t]{2}{*}{$0.5 \pm 0.0$} & \multirow[t]{2}{*}{1.5} & S1-1 & 502 & Screened \\
\hline & & & & $\mathrm{S} 1-2$ & 555 & Screened \\
\hline & & \multirow[t]{3}{*}{$1.1 \pm 0.3$} & \multirow[t]{3}{*}{1.7} & S2-1 & 523 & Screened \\
\hline & & & & S2-2 & 548 & Screened \\
\hline & & & & $\mathrm{S} 2-3$ & 594 & Screened \\
\hline & & \multirow[t]{3}{*}{$1.5 \pm 0.4$} & \multirow[t]{3}{*}{1.7} & S3-1 & 502 & Screened \\
\hline & & & & S3-2 & 519 & Screened \\
\hline & & & & S3-3 & 550 & Screened \\
\hline & & \multirow[t]{2}{*}{$2.1 \pm 0.4$} & \multirow[t]{2}{*}{1.4} & S4-1 & 500 & Screened \\
\hline & & & & S4-2 & 547 & Screened \\
\hline & & \multirow[t]{2}{*}{$3.1 \pm 0.3$} & 1.3 & S5-1 & 497 & Screened \\
\hline & & & & S5-2 & 550 & Screened \\
\hline & & & & S6-2 & 476 & Screened \\
\hline & & & & S6-3 & 502 & Screened \\
\hline & & $4.6 \pm 0.6$ & 1.2 & S7-1 & 456 & Screened \\
\hline & & & & S7-2 & 501 & Screened \\
\hline & & $5.8 \pm 0.9$ & 1.2 & S8-1 & 500 & Screened \\
\hline & & & & S8-2 & 424 & Screened \\
\hline & & & & S8-3 & 456 & Screened \\
\hline $\mathrm{N}$-sample & Melt forms & $2.2 \pm 0.7$ & 1.7 & N1-1 & 431 & Natural \\
\hline & & & & $\mathrm{N} 1-2$ & 488 & Light compacted \\
\hline & & & & $\mathrm{N} 1-3$ & 631 & Hard compacted \\
\hline & & $1.1 \pm 0.4$ & 1.7 & $\mathrm{~N} 2-1$ & 421 & Natural \\
\hline & & & & N2-2 & 492 & Light compacted \\
\hline & & & & $\mathrm{N} 2-3$ & 575 & Hard compacted \\
\hline & & $1.8 \pm 0.6$ & 1.8 & N3-1 & 361 & Natural \\
\hline & & & & N4-2 & 608 & Hard compacted \\
\hline & & $2.1 \pm 0.7$ & 1.8 & N5-1 & 396 & Natural \\
\hline & & & & N5-2 & 508 & Hard compacted \\
\hline & & $1.6 \pm 0.6$ & 1.8 & N6-1 & 378 & Natural \\
\hline & & & & N6-2 & 478 & Light compacted \\
\hline & & & & N6-3 & 636 & Hard compacted \\
\hline & & $4.1 \pm 1.6$ & 1.8 & N7-1 & 370 & Natural \\
\hline & & & & N7-2 & 551 & Hard compacted \\
\hline & & $2.2 \pm 0.7$ & 1.8 & N8-1 & 513 & Light compacted \\
\hline & & & & N8-2 & 635 & Hard compacted \\
\hline & & $1.4 \pm 0.5$ & 1.8 & N9-1 & 399 & Natural \\
\hline & & & & N9-2 & 462 & Light compacted \\
\hline & & & & N9-3 & 489 & Light compacted \\
\hline & & & & N9-4 & 590 & Hard compacted \\
\hline & & $1.8 \pm 0.6$ & 1.8 & N10-1 & 461 & Natural \\
\hline & & & & N10-2 & 463 & Natural \\
\hline & & $2.0 \pm 0.7$ & 2.0 & N11-1 & 565 & Light compacted \\
\hline & & $2.1 \pm 0.7$ & 2.0 & N12-1 & 388 & Natural \\
\hline & & & & N12-2 & 509 & Light compacted \\
\hline & & & & N12-3 & 607 & Hard compacted \\
\hline & Rounded grains & $0.4 \pm 0.1$ & 1.8 & N13-1 & 381 & Natural \\
\hline & & & & N13-2 & 480 & Light compacted \\
\hline & & & & N13-3 & 508 & Hard compacted \\
\hline & & $0.9 \pm 0.4$ & 1.8 & N14-1 & 366 & Natural \\
\hline & & & & N14-2 & 618 & Hard compacted \\
\hline & & $0.3 \pm 0.1$ & 1.8 & N15-1 & 363 & Natural \\
\hline & & & & N15-2 & 431 & Hard compacted \\
\hline & & $0.3 \pm 0.1$ & 1.9 & N16-1 & 390 & Natural \\
\hline & & & & N16-2 & 401 & Hard compacted \\
\hline
\end{tabular}



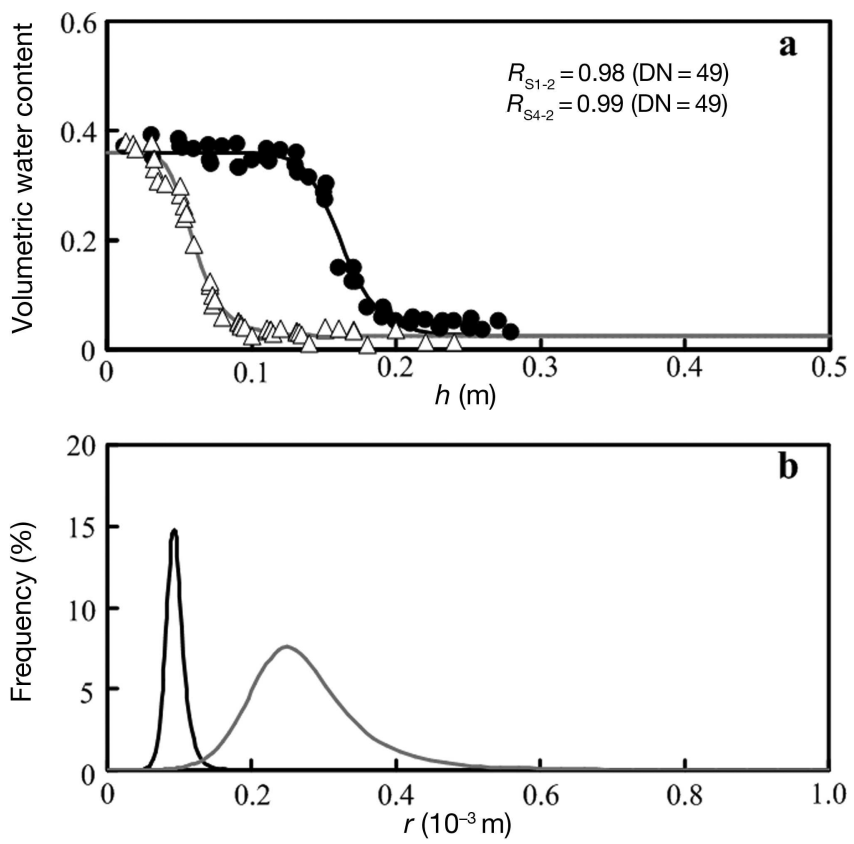

Fig. 1. Experimental and simulation results for samples with the same density but different grain sizes. (a) Experimental results with the modelled water retention curves. Black circles: measured results for S1-2 $\left(d=0.5 \mathrm{~mm}, \rho=555 \mathrm{~kg} \mathrm{~m}^{-3}\right)$. Black line: VG model simulation for S1-2. White triangles: measured results for S4-2 $\left(d=2.1 \mathrm{~mm}, \rho=547 \mathrm{~kg} \mathrm{~m}^{-3}\right)$. Grey line: VG model simulation for S4-2. (b) Frequency of the capillary tube plotted against all capillary tubes calculated from the VG model simulation. Black line: simulation for S1-2. Grey line: simulation for S4-2. DN is plotted data number.

and these values are approximately one order of magnitude smaller than the respective values of mean grain diameter $d$. Comparing the shapes of both $F(r)$ distributions, the concentration ratio of $r$ for $\mathrm{S} 1-2$ is narrower than that for S4-2, although both samples have the same bulk dry density. These calculated results imply that an increase in grain size causes an increase in pore size and a decrease in the uniformity of pore size.

Figure 2a shows the measured WRCs of the N-samples (N3-1 and N3-2) with the VG model simulations. Both Nsamples originated in the same snow layer (melt forms and $d=1.8 \mathrm{~mm}$ ), but their densities were different because N3-2 was tamped to obtain higher density. The bulk dry densities, $\rho$, of samples N3-1 and N3-2 were 361 and $621 \mathrm{~kg} \mathrm{~m}^{-3}$, respectively (Table 1 ). The WRCs for the two samples differed markedly, although the grain size was the same. Figure $2 \mathrm{~b}$ shows the $F(r)$ calculated from each VG model simulation. The $r$ peak of $\mathrm{N} 3-1(0.63 \mathrm{~mm})$ is larger than that of N3-2 $(0.17 \mathrm{~mm})$. Their values are smaller than $d(1.8 \mathrm{~mm})$, but the position of the $r$ peak of N3-2 is approximately one order of magnitude smaller than $d$, which is the same trend as for S1-2 and S4-2, whereas that of N3-1 is only one-third smaller than $d$. These differences should be due to the bulk dry density difference: N3-1 is less dense than S1-2 and S42, whereas N3-2 is similar to S1-2 and S4-2. Therefore, the relationship between the position of $r$ and $d$ depends strongly on the sample bulk dry density. Comparing the shapes of $F(r)$, the concentration ratio of $r$ for N3-1 is wider than that for N3-2. This difference may result from the fact that large pores are most easily crushed as density increases with compaction.
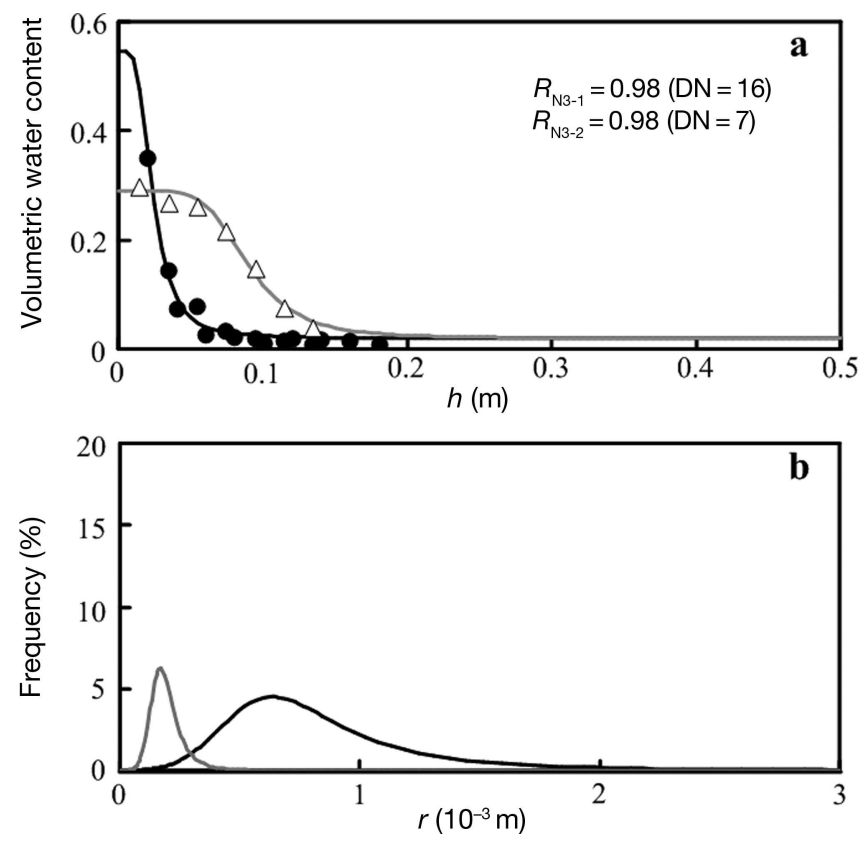

Fig. 2. Experimental and simulation results for samples with the same grain size but different densities. (a) Experimental results with the modelled water retention curves. Black circles: measured results for N3-1 $\left(d=1.8 \mathrm{~mm}, \rho=361 \mathrm{~kg} \mathrm{~m}^{-3}\right)$. Black line: VG model simulation for N3-1. White triangles: measured results for N3-2 $\left(d=1.8 \mathrm{~mm}, \rho=621 \mathrm{~kg} \mathrm{~m}^{-3}\right)$. Grey line: VG model simulation for N3-2. (b) Frequency of the capillary tube plotted against all capillary tubes calculated from the VG model simulation. Black line: simulation for N3-1. Grey line: simulation for N3-2. DN is plotted data number.

\subsection{Description of WRC of snow using grain size and bulk dry density}

Having discussed that the WRC of snow changed with its grain size, $d$, and dry bulk density, $\rho$, we now consider the possibility of describing the WRC of snow using $d$ and $\rho$. Coléou and Lesaffre (1998) introduced the parameter $d / \rho$ to model the air-entry suction, $h_{\text {air, }}$ of snow, which is the point at which air enters a sample. Similar to their idea, we introduced a parameter $\rho / d$ and examined its relationships to the parameters in the VG model. We adopted the inverse function compared to that of Coléou and Lesaffre (1998) because $\alpha$ in the VG model is related to the inverse of $h_{\text {air }}$. To discuss the relationship between the parameters in the VG model and $\rho / d$, we examined the results for the S-samples with uniform grain size because some of the $\mathrm{N}$-samples had various grain sizes (low uniformity) and a lower correlation coefficient for experimental measurements vs the fitted values of the VG model. Figure $3 a$ and $b$ show the relationships between the parameters $\alpha$ and $n$ of the VG model and $\rho / d(\mathrm{DN}=20)$. Both $\alpha$ and $n$ depend strongly on the value of $\rho / d$ : $\alpha$ increases quickly as $\rho / d$ decreases, whereas $n$ increases with $\rho / d$. The VG model parameters have the following relationships to $\rho / d$ with high correlation coefficients, $R$ :

$$
\begin{gathered}
\alpha=4.4 \times 10^{6}\left(\frac{\rho}{d}\right)^{-0.98}(R=0.98) \\
n=1+2.7 \times 10^{-3}\left(\frac{\rho}{d}\right)^{0.61}(R=0.93) .
\end{gathered}
$$

Having shown the good relationship between the parameters 

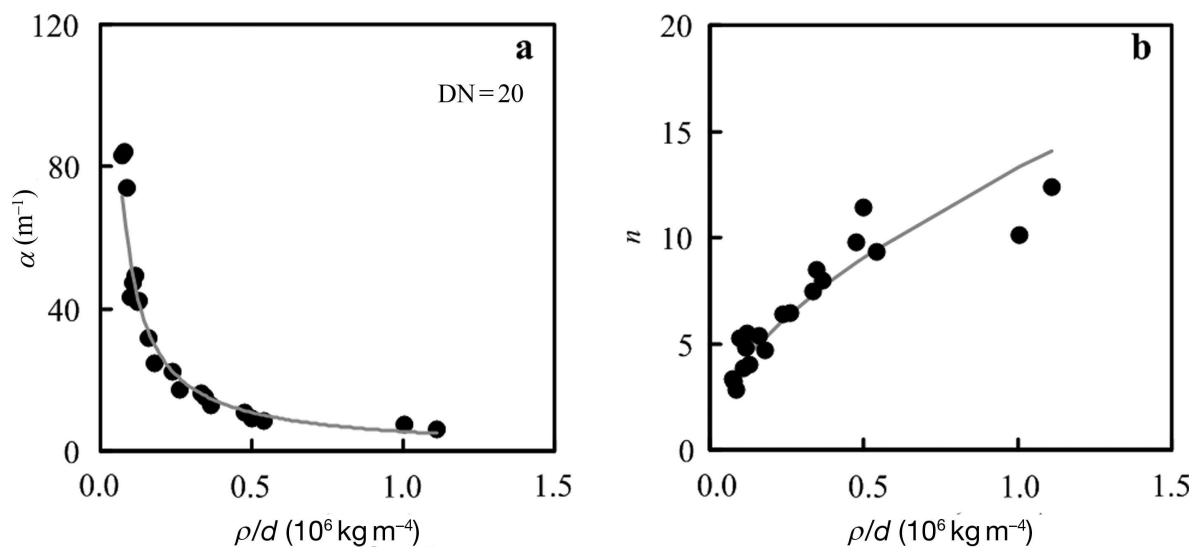

Fig. 3. Dependence of the parameters in the VG model on $\rho / d$ for the S-samples. (a) $\alpha$ in the VG model. (b) $n$ in the VG model. DN is plotted data number.

of the VG model and $\rho / d$, we consider the physical meaning of $\rho / d$. Assuming that the snow sample is composed of ice crystals with grain size $d, \rho$ is described as

$$
\rho=\frac{\left[N \times \frac{4}{3} \pi\left(\frac{d}{2}\right)^{3} \rho_{\mathrm{i}}\right]}{V_{0}}
$$

Here $V_{0}$ is the sample unit volume, $N$ is the total number of ice crystals in the unit volume and $\rho_{\mathrm{i}}$ is the density of ice. Introducing $\rho / d$ into Eqn (8) gives

$$
\frac{\rho}{d}=\frac{\left[N \times \frac{4}{3} \pi\left(\frac{d}{2}\right)^{3} \rho_{\mathrm{i}}\right] / V_{0}}{d} \propto \frac{N \times 4 \pi\left(\frac{d}{2}\right)^{2}}{V_{0}} .
$$

The right-hand side term in Eqn (9) is the total area of all ice crystal surfaces in the unit volume, i.e. the total surface area of all tubes (pores) in the unit volume. Therefore, $\rho / d$ is nearly equivalent to the specific surface area of a unit volume of snow $\left(\mathrm{SSA}_{v}\right)$. Because the specific surface area is thought to be an important physical property of snow (e.g. Arakawa and others, 2009), we investigated the use of another definition of specific surface area to describe the parameters $\alpha$ and $n$ of the VG model; namely, we applied the total surface area per unit weight $\left(\mathrm{SSA}_{w}\right)$ and made estimates using measured $d$ and $\rho_{\mathrm{i}}$ $\left(\mathrm{SSA}_{w}=6 /\left(d \rho_{\mathrm{i}}\right)\right)$. The relationship between the parameters $(\alpha$ and $n$ ) and $\mathrm{SSA}_{w}$ showed functions similar to those of Eqns (6) and (7), but their correlation coefficients, $R$, were lower than those of $\rho / d(R=0.94$ for $\alpha$ and $R=0.89$ for $n)$. Moreover, $S S A_{w}$ is considered to have the greatest influence over $d$ but not over $\rho$, which also controls the form of the WRC of snow (Fig. 2a). Based on these results, we considered that $\rho / d$, which is related to $S A_{v}$, is better than $S_{S A}$ when describing the parameters in the VG model. We thus used $\rho / d$ in ensuing analyses of samples of different densities.

Next, we examined the relationships between the parameters for the WRC of natural snow having a non-uniform grain size and $\rho / d$. Figure $4 \mathrm{a}$ and $\mathrm{b}$ present the relationships of the parameters $\alpha$ and $n$ of the VG model for natural snow and $\rho / d$ with the regression curves described using Eqns (6) and (7). Figure 4a shows a relationship similar to that of the S-samples between $\alpha$ and $\rho / d$, i.e. $\alpha$ increases as $\rho / d$ decreases. A function similar to that of Eqn (6) (power function of $\rho / d$ ) was applied to describe $\alpha$ for all data for the $\mathrm{N}$-samples $(\mathrm{DN}=41)$. A high correlation between $\alpha$ and the power function of $\rho / d$ was obtained $(R=0.72)$, although its coefficient and multiplier were different from those of Eqn (6). Analysis of each grain type showed that the melt forms had a high correlation coefficient $(R=0.82$ with $D N=29$ ), whereas the rounded grains had a low correlation coefficient $(R=0.48$ with $\mathrm{DN}=12)$. Therefore, the high correlation between $\alpha$ for all data of $\mathrm{N}$-samples and $\rho / d$ reflects the good relationship between the melt-form $\alpha$ values and $\rho / d$. In Figure $4 \mathrm{~b}$, the relationship between $n$ and $\rho / d$ differs for each grain type. For the melt forms, $n$ shows a dependence on $\rho / d$ that is similar to that of the S-samples ( $n$ increases as $\rho / d$ increases) and has a high correlation coefficient $(R=0.61)$ when a function similar to that of Eqn (7) $(1+$ power function of $\rho / d)$ was applied in describing its relationship with $\rho / d$. On the other hand, $n$ values for rounded grains appear to be independent of $\rho / d$ and no correlation between $n$ and $\rho / d$ was observed $(R=0.04)$. These results suggest that the WRC of the melt forms in the snow-cover model can be modelled using $d$ and $\rho$ based on functions similar to those of Eqns (6) and (7), whereas we need to introduce another formula and/or a new parameter to describe the WRC of the rounded grains.

We examined why the relationship between the two parameters and $\rho / d$ depended on grain type. As shown in Table 1, the ranges of bulk dry density variation of melt forms and rounded grains in the $\mathrm{N}$-samples are almost the same $\left(300-600 \mathrm{~kg} \mathrm{~m}^{-3}\right)$, whereas the grain sizes, $d$, of rounded grains are obviously smaller than those of the melt forms ( $d$ of rounded grains: $0.5-1.0 \mathrm{~mm}$; $d$ of melt forms: $1.0-4.0 \mathrm{~mm}$ ). Therefore, non-uniform grain size probably has a more important influence on pore-size uniformity for rounded grains than for melt forms because rounded grains have a small $d$. A decrease in pore-size uniformity should affect the values of $\alpha$ and $n$ via the change in distribution of capillary tube diameter related to the shape of WRC (see Section 3.1). In fact, despite their non-uniform grain size, the melt forms of the $\mathrm{N}$-samples show a dependence of $\alpha$ and $n$ on $\rho / d$ that is similar to that of the S-samples, which have a uniform grain size (Table 1). Another reason may be the effect of grain shape. The melt forms tended to be very round and sphere-like, whereas the rounded grains were of various shapes (e.g. elliptical). These differences may affect the parameterization results because we considered each grain to be a sphere. Moreover, there were many connections among grains, and cluster structures were locally present in the $\mathrm{N}$-samples. These complicated structures could cause a mismatch between the real representative size of structures and mean grain diameter as determined by measurement of individual grains. 

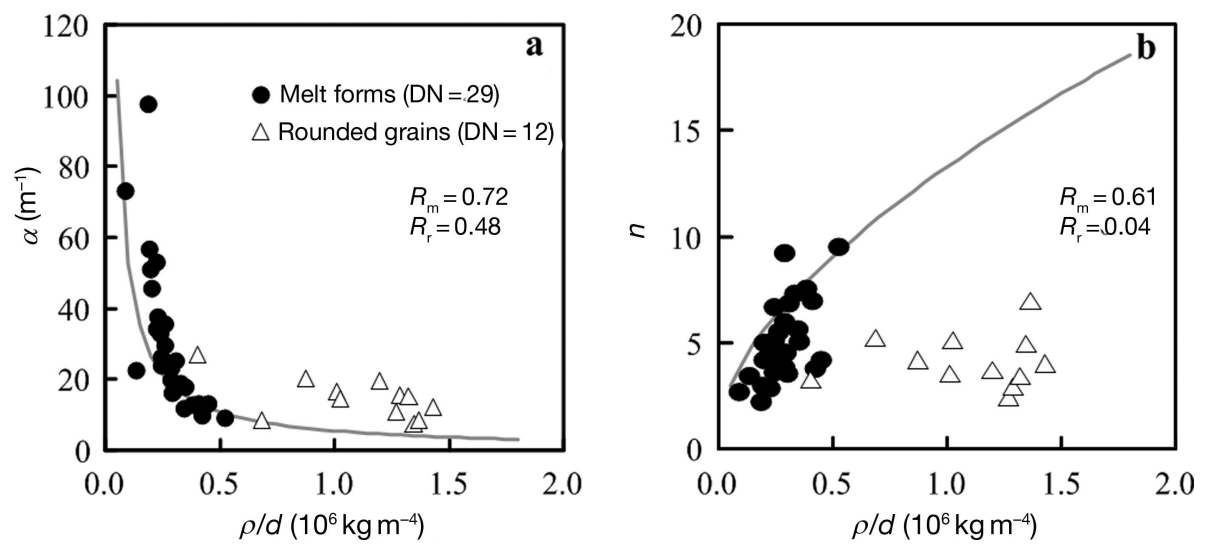

Fig. 4. Dependence of the parameters in the VG model on $\rho / d$ for the N-samples. (a) $\alpha$ in the VG model. (b) $n$ in the VG model. Black circles: results for melt forms. White triangles: rounded grains. Grey lines; regression curves calculated using Eqns (6) and (7). DN is plotted data number. $R_{\mathrm{m}}$ is correlation coefficient of melt forms. $R_{\mathrm{r}}$ is correlation coefficient of rounded grains.

\section{CONCLUSIONS}

The dependence of WRCs on characteristics of snow (grain size, bulk dry density and grain type) was examined using various snow samples. The analyses using the VG model gave the following results:

1. The distribution of pore size depended strongly on the sample grain size, $d$, and bulk dry density, $\rho$. The position of the peak pore size decreased when $d$ became smaller ( $\rho$ became larger), and the concentration ratio of pore size increased when $d$ became smaller ( $\rho$ became larger).

2. The WRC of melt forms can be described as a function of $\rho / d$, whereas rounded non-uniform grains did not show a good relation with $\rho / d$. Therefore, we should consider not only $d$ and $\rho$ but also grain type when modelling the WRC of snow.

In this study, using simple ideas based on soil physics, we have shown the possibility of modelling the WRC of snow using its characteristics, but we have not yet established a model. To introduce the influence of grain type in the model, it is necessary to translate grain type into physical parameters. It may be useful to introduce the idea of 'sphericity', which is used in numerical snow-cover models (Brun and others, 1989, 1992; Lehning and others, 2002a). The eventual establishment of a final model describing realistic water movement through snow cover and illustrating the dependence of hydraulic properties such as WRC and $K$ on snow characteristics will require future experiments that incorporate the true porosity structure of real snow.

\section{ACKNOWLEDGEMENTS}

We gratefully acknowledge the comments of Y. Ishii and Y. Kodama of Hokkaido University and thank the members of the Snow and Ice Research Center, National Research Institute for Earth Science and Disaster Prevention, for helpful discussions. Helpful comments and suggestions from two anonymous reviewers and the scientific editor, B. Turnbull, are greatly appreciated. We also thank S. Nakatsubo of Hokkaido University for providing the experimental system used in this study. We are grateful to $\mathrm{N}$. Tsuchida, who helped to analyse the distributions of the snow sample grain sizes.

\section{REFERENCES}

Arakawa H, Izumi K, Kawashima K and Kawamura T (2009) Study on quantitative classification of seasonal snow using specific surface area and intrinsic permeability. Cold Reg. Sci. Technol., 59(2-3), 163-168 (doi: 10.1016/j.coldregions.2009.07.004)

Bartelt P and Lehning M (2002) A physical SNOWPACK model for the Swiss avalanche warning. Part I: numerical model. Cold Reg. Sci. Technol., 35(3), 123-145 (doi: 10.1016/S0165-232X(02) 00074-5)

Brooks RH and Corey AT (1964) Hydraulic properties of porous media. Colorado State University, Fort Collins, CO (Hydrology Papers 3)

Brun E, Martin E, Simon V, Gendre C and Coléou C (1989) An energy and mass model of snow cover suitable for operational avalanche forecasting. J. Glaciol., 35(121), 333-342

Brun E, David P, Sudul M and Brunot G (1992) A numerical model to simulate snow-cover stratigraphy for operational avalanche forecasting. J. Glaciol., 38(128), 13-22

Colbeck SC (1974) The capillary effects on water percolation in homogeneous snow. J. Glaciol., 13(67), 85-97

Colbeck SC (1975) A theory for water flow through a layered snowpack. Water Resour. Res., 11(2), 261-266

Coléou C and Lesaffre B (1998) Irreducible water saturation in snow: experimental results in a cold laboratory. Ann. Glaciol., 26, 64-68

Fierz C and 8 others (2009) The international classification for seasonal snow on the ground. UNESCO-International Hydrological Programme, Paris (IHP Technical Documents in Hydrology 83)

Hirashima H, Yamaguchi S, Sato A and Lehning M (2010) Numerical modelling of liquid water movement through layered snow based on new measurements of the water retention curve. Cold Reg. Sci. Technol., 64(2), 94-103 (doi: 10.1016/j.coldregions.2010.09.003)

Jury WA and Horton R (2004) Soil physics, 6th edn. Wiley, Hoboken, NJ

Klute A (1986) Water retention: laboratory methods. In Klute A ed. Methods of soil analysis, Part 1. Physical and mineralogical methods. American Soil Association and Soil Science Society of America, Madison, WI, 635-662 (Agronomy Monograph 9)

Kosugi K (1996) Lognormal distribution model for unsaturated soil hydraulic properties. Water Resour. Res., 32(9), 2697-2703 (doi: 10.1029/96WR01776)

Lehning M, Bartelt P, Brown B, Fierz C and Satyawali P (2002a) A physical SNOWPACK model for the Swiss avalanche warning. Part II: snow microstructure. Cold Reg. Sci. Technol., 35(3), 147-167 (doi: 10.1016/S0165-232X(02)00072-1)

Lehning M, Bartelt P, Brown B and Fierz C (2002b) A physical SNOWPACK model for the Swiss avalanche warning. Part III: 
meteorological forcing, thin layer formation and evaluation. Cold Reg. Sci. Technol., 35(3), 169-184 (doi: 10.1016/S0165232X(02)00072-1)

Mualem Y (1976) A new model for predicting the hydraulic conductivity of unsaturated porous media. Water Resour. Res., 12(3), 513-522 (doi: 10.1029/WR012i003p00513)

Sakai M and Toride N (2009) Hydraulic property models for water retention and unsaturated hydraulic conductivity. J. Jpn. Soc. Soil Phys., 111, 61-73 [In Japanese]

Sugie S and Naruse R (2000) Measurements of unsaturated hydraulic conductivity of snow. Seppyo, J. Jpn. Soc. Snow Ice, 62(2), 117-127 [In Japanese with English summary]

Van Genuchten MT (1980) A closed-form equation for predicting the hydraulic conductivity of unsaturated soils. Soil Sci. Soc. Am. J., 44(5), 892-898
Van Genuchten MT and Nielsen DR (1985) On describing and predicting the hydraulic properties of unsaturated soils. Ann. Geophys., 3(5), 615-628

Van Genuchten MT, Leij FJ and Yates SR (1991) The RETC code for quantifying the hydraulic functions of unsaturated soils. Robert $\mathrm{S}$ Kerr Environmental Research Laboratory, US Environmental Protection Agency, Ada, OK (EPA Report 600/2-91/065)

Wankiewicz A (1979) A review of water movement in snow. In Colbeck SC and Ray M eds. Proceedings of Modeling of Snow Cover Runoff, 26-28 September 1978, Hanover, New Hampshire. US Salinity Laboratory, Agricultural Research Service, US Department of Agriculture, Riverside, CA, 222-252

Yamaguchi S, Katsushima T, Sato A and Kumakura T (2010) Water retention curve of snow with different grain sizes. Cold Reg. Sci. Technol., 64(2), 87-93 (doi: 10.1016/j.coldregions.2010.05.008) 